\title{
ESTRATIGRAFIA DA SUCESSÃO SEDIMENTAR PÓS- BARREIRAS (ZONA BRAGANTINA, PARÁ) COM BASE EM RADAR DE PENETRAÇÃO NO SOLO.
}

\author{
Dilce F. Rossetti', Ana M. Góes² \& Lena S. B. Souza ${ }^{3}$
}

Received December 28, 2001 / Accepted August 30, 2002

\begin{abstract}
Investigação pioneira aplicando Radar de Penetração no Solo (GPR) na área da Praia do Atalaia, norte do Brasil, nos permitiu caracterizar, pela primeira vez, fácies e estratigrafia dos depósitos conhecidos informalmente como Sedimentos Pós-Barreiras (Plioceno e mais recente). Esta sucessão sedimentar recobre discordantemente o embasamento miocênico, representado pelas formações Pirabas/Barreiras. Três unidades estratigráficas foram reconhecidas. A Unidade 1, inferior, consiste em um intervalo com $6 \mathrm{~m}$ de espessura média dominado por reflexões pobremente definidas e de baixa amplitude, e que intergradam com reflexões de média escala dos tipos tangencial, obliquo e hummocky. A Unidade 2, intermediária, possui cerca de $9 \mathrm{~m}$ de espessura e inclui, principalmente, reflexões oblíquas de larga escala, cujas configurações variam de paralela, tangencial, sigmoidal a sigmoidal-complexa. A Unidade 3 , superior, corresponde a um intervalo entre 3,5 e $9 \mathrm{~m}$ de espessura, sendo dominada por reflexões hummocky, seguidas por reflexões de média escala dos tipos oblíquo, paralelo a sub-paralelo, e em corte-e-preenchimento. A análise da configuração das reflexões internas e geometria das reflexões nos leva a propor que a unidade correspondente aos Sedimentos Pós-Barreiras é mais variável faciologicamente que inicialmente imaginado, incluindo depósitos eólicos (dunas costeiras), bem como depósitos de cordão litorâneo, planície de maré, canal e mangue. Além disto, o mapeamento das três unidades descritas acima é importante para desvendar a complexidade de sedimentação versus erosão durante o Neógeno tardio no norte do Brasil.
\end{abstract}

Palavras-chave: Radar de penetração no solo; Neógeno; Zona Bragantina; Norte do Brasil; Estratigrafia; Análise de fácies.

STRATIGRAPHY OF THE PÓS-BARREIRAS SEDIMENTARY SUCCESSION (BRAGANTINE ZONE, PARA) BASED ON GROUND PENETRATING RADAR - Ground penetrating radar $(G P R)$ is a geophysical method that consists in the emission of electromagnetic waves of high frequency (between 10-2500 Mhz). This equipment has been increasingly applied for mapping of physical properties and chemical compositions of rocks at shallow depth, as well as for stratigraphic and facies analysis. The application of this methodology in Brazil is still reduced to a few studies, mostly emphasizing soil stratigraphy and eolian paleoenvironments. However, previous studies undertaken in northern Brazil have demonstrated that, in combination with traditional studies using outcrop data, the GPR might be a powerful additional tool to help correlating sedimentary successions and reconstruct depositional environments throughout the Neogene in the Bragantina Zone. In this paper, we will document a pioneer investigation applying a SYR-2 GPR system (Geophysical Survey Systems Inc.) in the Praia do Atalaia area, Salinópolis, northern Brazil, which allowed us to characterize, for the first time, facies and stratigraphy of the deposits known informally as PósBarreiras Sediments (Pliocene and younger). The equipment was operated using a $200 \mathrm{Mhz}$ monostatic antenna in continuous mode. The acquired sections were processed using the RADANWIN software in order to increase the reflection resolution and thus allow a refined interpretation of the sections. Based on this procedure, it was noticed that the studied sedimentary succession overlies unconformably the Miocene basement, represented by the Pirabas/Barreiras formations. Three stratigraphic units were also distinguished. The lowermost 
Unit 1 consists of an interval up to $6 \mathrm{~m}$ thick dominated by poorly-defined, low amplitude reflections, which intergrade with medium-scale, tangential oblique and hummocky reflections. This unit revealed to be discontinuous throughout the studied radar sections, occurring mainly where the Miocene basement is depressed. The middle Unit 2 is circa $9 \mathrm{~m}$ thick and mostly includes large-scale oblique reflections varying in style from parallel, tangential, sigmoidal to sigmoidal-complex. The two latter ones might reach up to $7 \mathrm{~m}$ thick. A strong, high amplitude and laterally continuous reflection marks the top of Unit 2, forming a bounding surface having local depressions of up to $40 \mathrm{~m}$ in relief. The uppermost Unit 3 corresponds to an interval ranging from 3.5 to $9 \mathrm{~m}$ thick, which is dominated by hummocky reflections, followed by medium-scale oblique, parallel to sub-parallel and cut and fill reflections. The GPR data allows the interpretation that the Pós-Barreiras Sediments were unconformably deposited over the Miocene deposits, as revealed by the mapping of an erosional bounding surface at the base of Unit 1. In addition, the analysis of internal reflection configurations and reflection geometries led us to propose that the Pós-Barreiras Sediments is more variable in terms of facies than previously thought, including eolian deposits (coastal dunes), as well as beach ridge, tidal flat, channel and mangrove deposits. Furthermore, the mapping of the three stratigraphic units described above is important to unravel the complexity of sedimentation versus erosion during the latest Neogene in northern Brazil. The conclusions obtained from the GPR data lead to suggest a drop in relative sea level after the end of the Miocenelower Pliocene in the Bragantina Zone, which was followed by a transgression and deposition of Unit 1 along embayments and adjacent eolian dunes and/or beach ridges. Renewed phase of relative sea level drop took place, which led to erosion of the uppermost portions of Unit 1, forming a bounding surface that is locally cut by fluvial channel scouring. Large-scale eolian dunes laterally intergraded with tidal flat, filling the depressions formed by channel erosion during a subsequent transgressive phase. At least one more drop in relative sea level appears to have taken place in the study area, as revealed by the discontinuity surface between units 2 and 3, which is in turn mantled by modern sedimentation along mangroves, tidal channels and coastal dune environments.

Key words: Ground penetrating radar; Neogene; Bragantina Zone; Northern Brazil; Stratigraphy; Facies analysis.

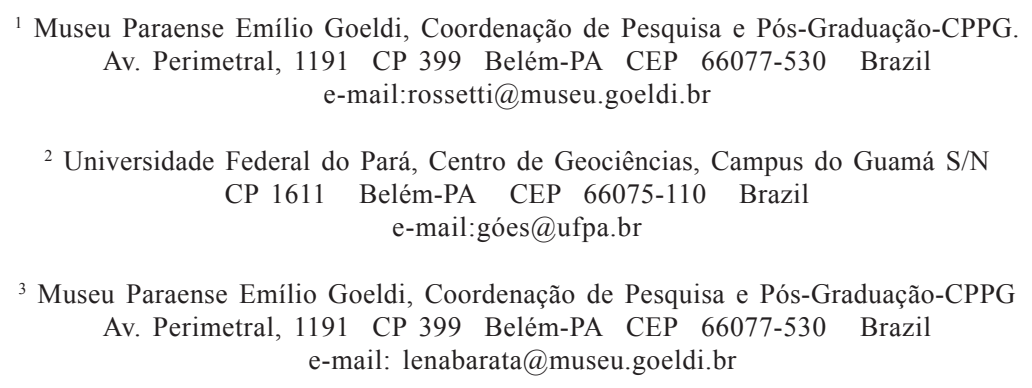

\section{INTRODUÇÃO}

O radar de penetração no solo (GPR) vem sendo cada vez mais utilizado no mapeamento das propriedades físicas e na determinação da composição química das rochas a profundidades rasas, visando-se melhorar a base de dados em estudos enfocando principalmente a análise estratigráfica, a reconstrução de ambientes deposicionais, a caracterização de aqüíferos e a engenharia civil (p.e., Van Heteren et al., 1998; Knoll et al., 1991; Bridge et al., 1995; Asprion, 1998; Dagallier et al., 2000). Apesar disto, este tipo de investigação é ainda pioneira no Brasil, sendo os poucos trabalhos publicados voltados à estratigrafia de solos (Ucha et al., 1999) e à análise de estruturas em paleoambientes eólicos (Silva \& Scherer, 2000). Mais recentemente, se demonstrou a grande aplicabilidade deste método como ferramenta auxiliar na análise estratigráfica e no reconhecimento de ambientes deposicionais terciários da Zona Bragantina, nordeste do Estado do Pará, favorecendo a ampliação da base de dados desta área, caracterizada por afloramentos escassos e/ou descontínuos (Rossetti \& Góes, 2001). O sucesso obtido neste trabalho motivou a continuidade de 
investigações desta natureza com o intuito de ampliar as informações sedimentológicas e estratigráficas referentes às sucessões terciárias e quaternárias na região norte-brasileira, aonde estes depósitos vêm sendo mais sistematicamente investigados utilizandose dados de afloramentos (p.e.,. Arai et al., 1988; Rossetti et al., 1989, 1990; Góes et al., 1990; Arai, 1997; Leite et al., 1997a,b; Rossetti, 2000, 2001). O detalhamento dos depósitos terciários e quaternários que ocorrem ao longo do litoral norte do Brasil é de fundamental importância para a caracterização dos eventos geológicos que marcaram o período Neógeno na escala mundial, uma vez que eles não se constituem em eventos isolados, mas documentam uma história de flutuação do nível do mar consistente com muitas outras áreas da América do Sul e do mundo, refletindo mudanças eustáticas, provavelmente combinadas a fatores tectônicos (Rossetti, 2001; Rossetti \& Góes, 2001). Os estudos conduzidos até o momento no nordeste da Amazônia vêm dando maior ênfase às unidades terciárias, conhecidas como sucessão Pirabas/Barreiras, enquanto que os depósitos sobrejacentes, inseridos genericamente como Sedimentos Pós-Barreiras (Plioceno?-Quaternário), são comparativamente muito menos conhecidos, o que tem limitado interpretações mais concretas a respeito de seu modo de formação e de sua evolução sedimentar. Isto é devido, em grande parte, ao seu registro inadequado, já que estes depósitos ocorrem formando uma delgada cobertura intemperizada sobre os depósitos da Formação Barreiras. Este estudo mostra que o GPR pode se apresentar como uma ferramenta complementar robusta no estudo dos Sedimentos Pós-Barreiras, permitindo sua melhor caracterização estratigráfica. Além disto, o estudo dos padrões de reflexões eletromagnéticas permite fazer inferências sobre os ambientes deposicionais, os quais se mostraram muito mais variados do que inicialmente imaginado pelo seu aspecto maciço dominante nos afloramentos. Espera-se que a base de dados de subsuperfície disponibilizadas no presente trabalho, embora ainda de caráter local, possa contribuir em um futuro próximo para orientar e motivar investigações mais detalhadas enfocando os Sedimentos Pós-Barreiras e, assim, aumentar o grau de precisão do registro dos eventos neógenos tardios no norte do continente sulamericano.

\section{METODOLOGIA}

O Radar de Penetração no Solo (GPR) é um método geofísico que consiste na emissão no solo de ondas eletromagnéticas de alta freqüência (geralmente entre 10 e $2500 \mathrm{Mhz}$ ), sendo parte desta energia refletida a uma antena receptora. Diferenças nas propriedades eletromagnéticas dos materiais atravessados (permissividade dielétrica, susceptibilidade magnética, condutividade elétrica) permitem inferências sobre a estratigrafia do subsolo raso, bem como determinações de contrastes litológicos e condições de umidade do solo. Os sinais de radar são registrados digitalmente em nanossegundos, representativos do intervalo de tempo entre o momento de emissão da onda até seu retorno em uma antena receptora deslocada ao longo de um transecto. A profundidade de investigação atingida por este método é, em média, de cerca de 10 a $15 \mathrm{~m}$, porém profundidades de penetração de até $50 \mathrm{~m}$ são possíveis em áreas com materiais de baixa condutividade. A resolução vertical atingida depende da profundidade da investigação, podendo ser aumentada com a elevação da freqüência da antena, o que porém introduz uma diminuição na penetração do sinal. Resoluções da ordem de até $2 \mathrm{~cm}$ têm sido registradas sob certas circunstâncias (Dagallier et al., 2000). Portanto, a escolha do tipo de antena a ser utilizada se constitui em uma importante fase durante as investigações, sendo fundamental para se atingir os resultados desejados.

Neste estudo utilizou-se o sistema de GPR SYR2 da Geophysical Survey Systems Inc., sendo os dados coletados em antena monoestática de $200 \mathrm{Mhz}$ ligada a um sistema de registro computadorizado. Esta antena foi a que se mostrou mais adequada para o tipo de investigação planejada, permitindo registrar toda a sucessão Pós-Barreiras, bem como o embasamento terciário até profundidades de cerca de $13 \mathrm{~m}$ e, ao mesmo tempo, com a manutenção de uma resolução que favoreceu a análise detalhada das características estratigráficas e faciológicas.

As seções GPR foram adquiridas em modo contínuo e velocidade de caminhamento constante, sendo o controle horizontal feito através de marcos espaçados a cada $50 \mathrm{~m}$. As condições de aquisição dos dados foram as seguintes: 512 amostras/ 
escaneamento, constante dielétrica de 3-5, faixa entre 150-180 ns, razão de transmissão $=64 \mathrm{Khz}$, filtro vertical de transmissão alta $=30 \mathrm{Mhz}$, filtro vertical de transmissão baixa $=400 \mathrm{Mhz}$ e ganhos ajustáveis para cada seção. O processamento final foi feito com o auxílio do programa RADANWIND, o qual permite melhorar a resolução das reflexões, bem como salientar feições específicas, além de facilitar a impressão das secções e gerenciamento dos dados de radar. Neste trabalho, o processamento pósaquisição foi mínimo, e consistiu na aplicação de filtros com resposta de impulso infinito e correção de ganhos, o que se mostrou de grande utilidade na eliminação ou aumento da amplitude das reflexões e, conseqüentemente, uma qualidade melhor dos sinais de radar.

O local escolhido para o detalhamento dos Sedimentos Pós-Barreiras foi a Praia do Atalaia, no município de Salinópolis (Fig. 1), devido à combinação dos seguintes fatores: 1. nesta área, e em seus arredores, ocorre um bom registro desta sucessão sedimentar, bem como de seu embasamento miocênico, como revelado em estudos anteriores (p.e., Arai et al., 1988; Rossetti et al., 1989, 1990; Góes et al., 1990; Arai, 1997; Leite et al., 1997a,b), o que possibilitou a calibragem do equipamento e as interpretações geológicas apresentadas neste trabalho; 2. esta é uma área relativamente plana, o que dispensou, em grande parte, maiores processamentos das seções visando-se sua correção topográfica; 3 . o local selecionado passa atualmente por um processo de urbanização crescente, o que tem resultado na abertura de ruas regularmente espaçadas que se prestam como vias ideais à passagem do GPR, resultando em uma malha natural com seções orientadas nos sentidos norte/sul e leste/oeste, o que

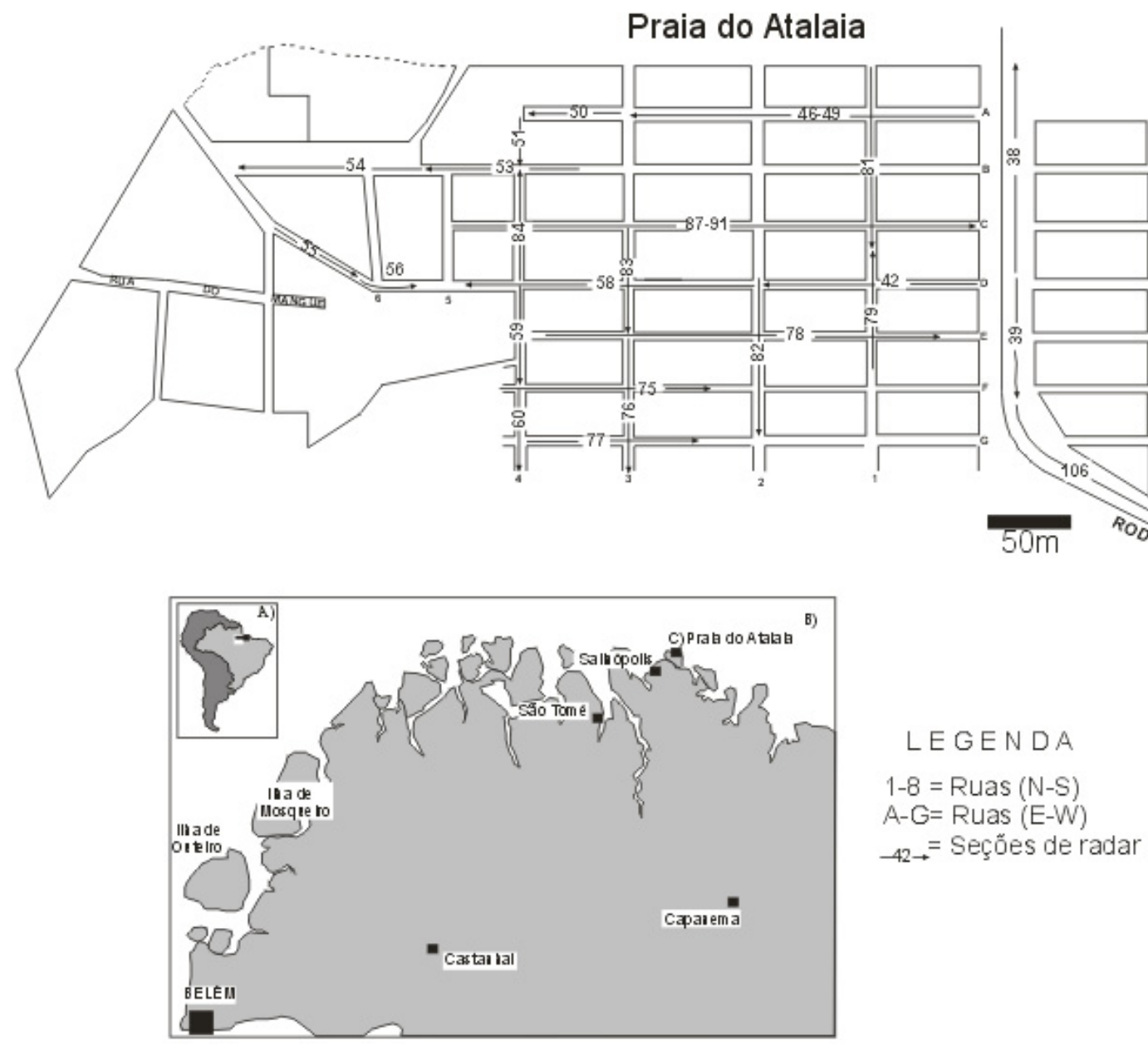

Figura 1 - Mapa da área de estudo na Praia do Atalaia, município de Salinópolis, com a localização das seções de radar ilustradas neste trabalho.

Figure 1 - Map of the study area in the Praia do Atalaia, Salinópolis district, with location of the radar sections illustrated in this paper. 
contribuiu para a visualização tri-dimensional dos estratos investigados; 4 . tendo-se em vista o acelerado processo de crescimento urbano e o grande interesse turístico da Praia do Atalaia, projetos de geologia ambiental vêm sendo realizados nesta área em função das peculiaridades do terreno dominado por ambientes recentes de mangue, dunas costeiras (ainda em atividade) e a presença de falésias sujeitas a forte efeito destrutivo pela ação de correntes de maré de alta amplitude que atingem este litoral. Assim, além de contribuir para o melhor entendimento dos eventos neógenos tardios, o sistema de perfilagem contínua com o GPR, como apresentado neste trabalho, poderá servir de apoio na condução de trabalhos futuros visando o planejamento urbano deste local.

\section{SÍNTESE GEOLÓGICA}

Os depósitos de idade cenozóica superior expostos na Zona Bragantina foram individualizados em três sucessões estratigráficas limitadas por discordâncias regionais e designadas de seqüência deposicional $\mathrm{A} \mathrm{a} \mathrm{C}$, similarmente à proposta para os depósitos neogênicos que ocorrem ao longo do litoral maranhense (Fig. 2; Rossetti, 2000, 2001). A Seqüência A (Fig. 3), correspondente ao termo litoestratigráfico Formação Pirabas e parte inferior da Formação Barreiras, é de idade oligocênica superior/ miocênica inferior e inclui calcários terrígenos, folhelhos negros carbonáceos e arenitos calcíferos interdigitados com argilitos e arenitos variegados. Estes depósitos são atribuídos a ambientes de plataforma externa, plataforma restrita/laguna e mangues/planícies de lama representativos de um sistema marinho marginal progradacional. A Seqüência $B$, de idade miocênica média, corresponde à porção intermediária da Formação Barreira, e é constituída de argilitos e arenitos variegados depositados em ambientes que variam de leques aluviais a marinho transicional dominado por maré (canal de maré, planície de maré e mangue), provavelmente com características estuarinas. A Seqüência $C$, objeto deste estudo, inclui indistintamente depósitos pliocênicos e mais jovens referenciados como Sedimentos Pós-Barreiras, cuja reconstituição do ambiente deposicional é ainda imprecisa, embora inclua, pelo menos em parte, depósitos formados por processos eólicos. Investigação preliminar de GPR demonstrou que na

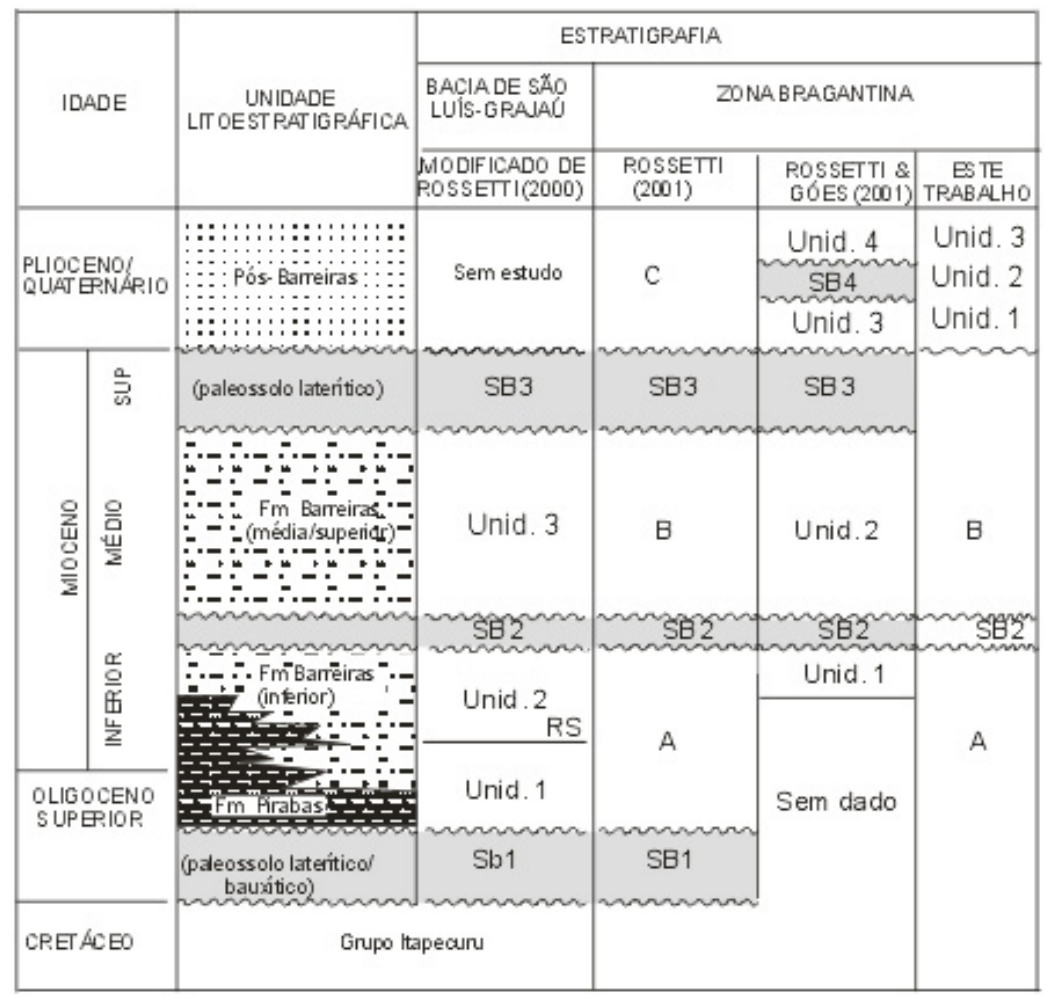

Figura 2 - Coluna estratigráfica da Zona Bragantina, como observado em diversas regiões da costa norte do Brasil.

Figure 2 - Stratigraphic column of the Bragantina Zone, as observed at several regions along the Brazilian northern coast. 


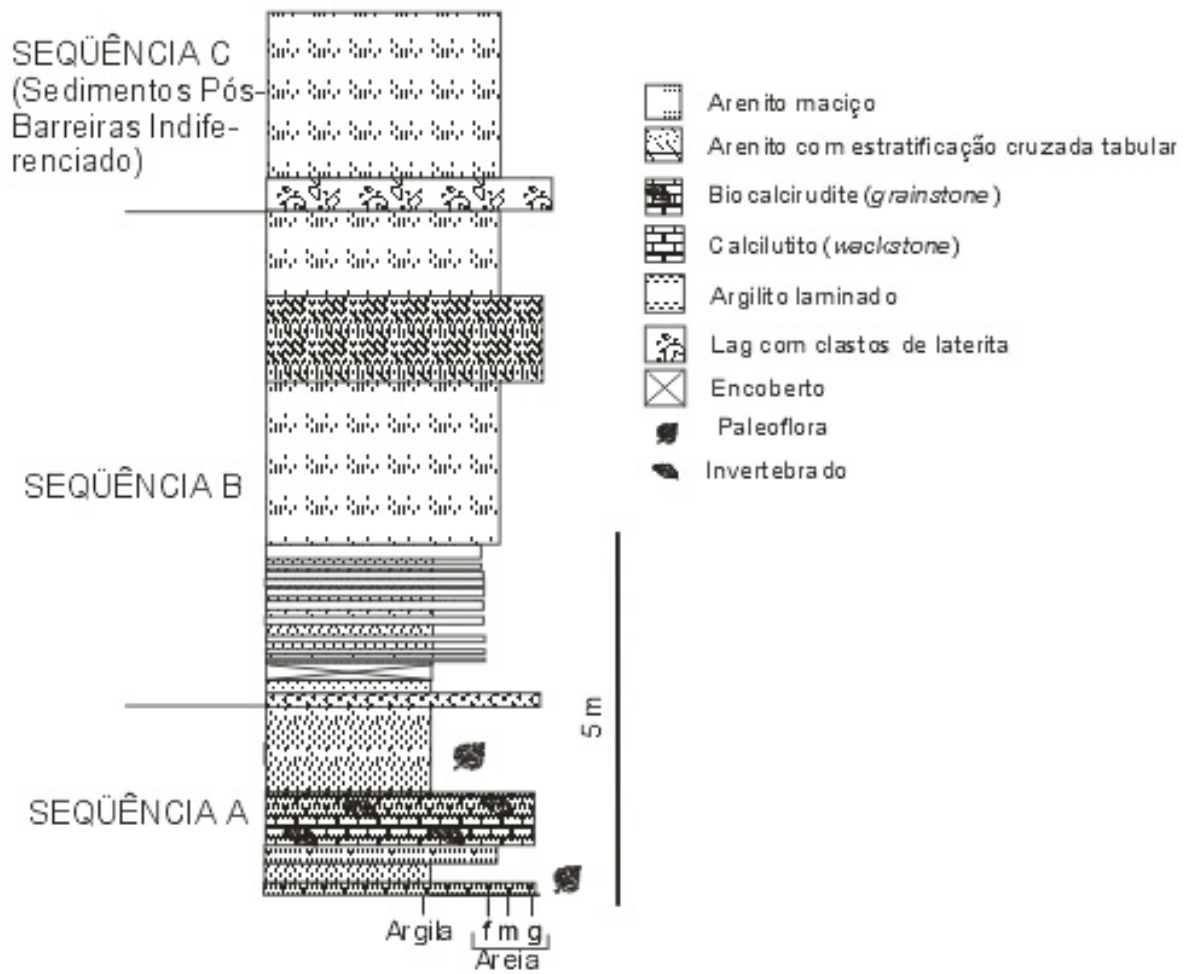

Figura 3 - Perfil litoestratigráfico representativo dos depósitos neógenos no município de Salinópolis, onde a área de estudo está localizada.

Figure 3 - Lithoestratigraphic profile representative of the Neogene deposits in the Salinópolis district, where the study area is located.

Ilha do Outeiro, município de Belém, os Sedimentos Pós-Barreiras podem ser subdividos em dois intervalos estratigráficos (unidades 3 e 4 ) separados por uma superfície de descontinuidade com caráter erosivo (SB4; Rossetti \& Góes, 2001). Baseado nas análises dos padrões de reflexões eletromagnéticas, os autores sugerem, ainda, que estes depósitos podem ser litologicamente mais variados do que se acreditava incluindo, além de arenitos, padrões típicos de litologias argilosas. No presente trabalho, foram definidos três intervalos estratigráficos nos Sedimentos Pós-Barreiras, aqui denominados de unidades 1, 2 e 3 , separados por superfícies de descontinuidades.

\section{ANÁLISE DOS PADRÕES DE REFLEXÕES}

As reflexões obtidas com o GPR são similares às reflexões sísmicas e, portanto, podem ser interpretadas tomando-se por base os mesmos parâmetros relativos à configuração e geometria na determinação dos ambientes deposicionais, bem como aos padrões de terminações das reflexões no mapeamento das unidades sedimentares (p.e., Payton, 1977; Van Heteren et al., 1998). Sete tipos de reflexões foram reconhecidos no presente trabalho, cujas descrições e interpretações são fornecidas abaixo. A interpretação geológica dos diferentes tipos de reflexões baseou-se em comparações com padrões de reflexões de radar obtidos em seções correlatas na Ilha do Outeiro (Rossetti \& Góes, 2001), bem como no conhecimento prévio da litologia dominante nesses depósitos como visto em afloramentos, a saber arenitos estratificados com feições eólicas e argilitos laminados a maciços.

\section{Tipo 1: superfície estratigráfica}

Descrição: constitui-se de reflexões de alta amplitude e alta continuidade lateral (Figs. 4A,B), que são concordantes ou truncam as reflexões sobrejacentes, sendo sobrepostas por outras reflexões, também concordantes, mas que, em algum momento ao longo de sua extensão, terminam em onlap ou downlap contra elas. As reflexões típicas deste padrão mostram-se fortemente irregulares, configurando desníveis superiores à resolução das seções, ou seja, maiores que $13 \mathrm{~m}$, podendo ser fortemente deprimidas em alguns segmentos quando 
assumem forma côncava. Até quatro reflexões deste tipo foram observadas nas seções analisadas, podendo haver a intercepção local de algumas delas, o que geralmente coincide com os setores onde estas reflexões mostram-se côncavas. Cada reflexão individual pode apresentar suas características multiplicadas até 3 ou 4 vezes abaixo dela, o que resulta em uma sinal bastante proeminente de fácil mapeamento através de toda a seção (Fig. 4B).

Interpretação: as reflexões do tipo 1 possuem características típicas de superfícies de descontinuidade que limitam conjuntos de estratos geneticamente relacionados, sendo consideradas como boas candidatas a superfícies de importante conotação estratigráfica na área de estudo. Esta interpretação é consistente com as seguintes observações: 1. extensão lateral significativa, sendo mapeável através de todas as seções de radar analisadas; e 2. caráter erosivo, revelado pelos padrões de terminações das reflexões sobre e

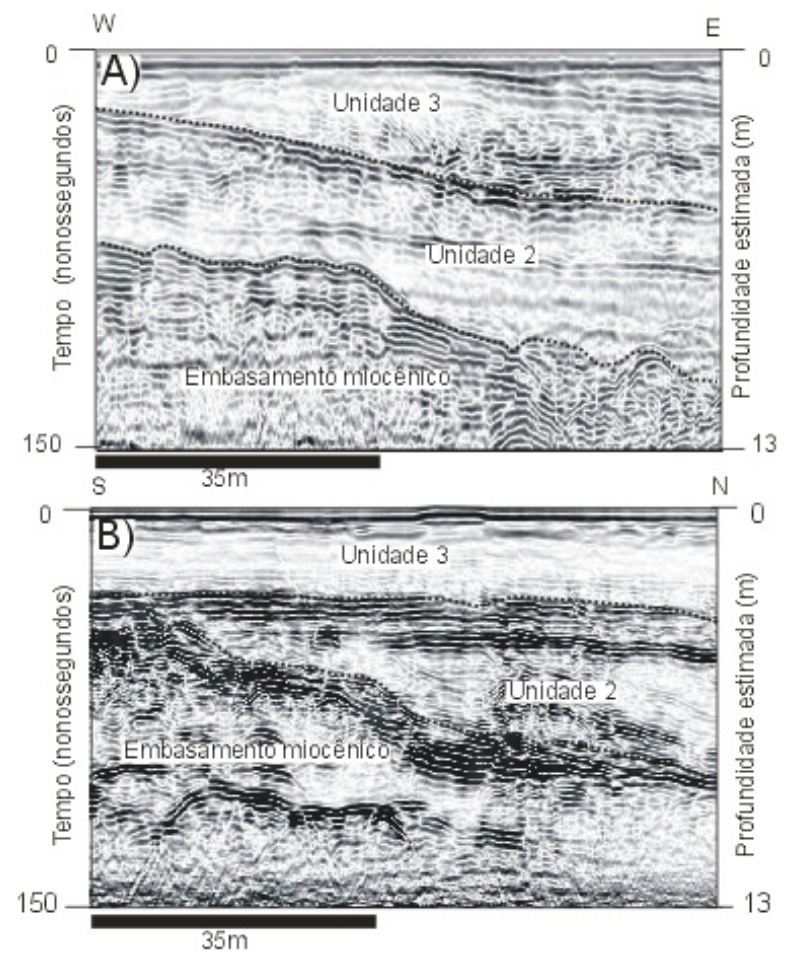

Figura 4 - Reflexões do tipo 1 (superfície estratigráfica) entre o embasamento miocênico e a Unidade 2 (inferior) e entre as unidades 2 e 3 (superior). A) Seção 50. B) Seção 83. Notar múltiplos que salientam ainda mais as reflexões do tipo 1. (Ver Fig. 1 para localização das seções).

Figure 4 - Type 1 reflections (stratigraphic surface) between Miocene basement and Unit 2 (lower) and between units 2 and 3 (upper). A) Section 50. B) Section 83. Note multiples that highlight even more the reflections of type 1. (See Fig. 1 for sections location). subjacentes, bem como pela distribuição irregular formando desníveis acentuados, atribuídos a relevo erosional. O mapeamento destas superfícies possibilitou o estabelecimento de uma estratigrafia detalhada para a área de estudo, como será discutido no decorrer deste trabalho.

\section{Tipo 2: paralelo a sub-paralelo}

Descrição: caracterizado por reflexões planas e de alta amplitude, que se sobrepõem umas às outras na direção vertical, formando uma série de reflexões intimamente espaçadas mais ou menos horizontalizadas (Fig. 5). As reflexões paralelas podem ser lateralmente contínuas ou descontínuas, neste último caso sendo formadas por uma série de reflexões interrompidas, que formam curtos segmentos planares sobrepostos. O conjunto de reflexões paralelas a sub-paralelas ocorre em pacotes com geometria que segue sua forma interna, configurando corpos em lençol ou tabulares.

Interpretação: este padrão de reflexão é geralmente relacionado a razões uniformes de deposição em ambiente plano, de baixa energia e caracterizado por predomínio de deposição de argila a partir de suspensões. Entretanto, este tipo de reflexão na área de estudo pode mostrar excelente penetração, o que leva a sugerir, em princípio, pobre conteúdo em lama. Uma possibilidade seria a deposição de areias com estratificação plano-paralela, tal como ocorre em ambientes de praia. Entretanto, pacotes argilosos com até $2 \mathrm{~m}$ de espessura em depósitos terciários na Ilha do Outeiro mostraram também excelente penetração, o que foi atribuído à presença de finas intercalações de arenito fino formando acamamentos heterolíticos horizontalizados, tipicamente correspondentes a planícies de maré (Rossetti \& Góes, 2001), o que pode também ser o caso na área de estudo.

\section{Tipo 3: hiperbólico}

Descrição: caracterizado por sinais de radar de freqüência moderada a alta, baixa continuidade lateral e amplitude elevada, que formam feições hiperbólicas isoladas ou em grupos, quando então ocorrem lateralmente dispostas umas às outras ou são 


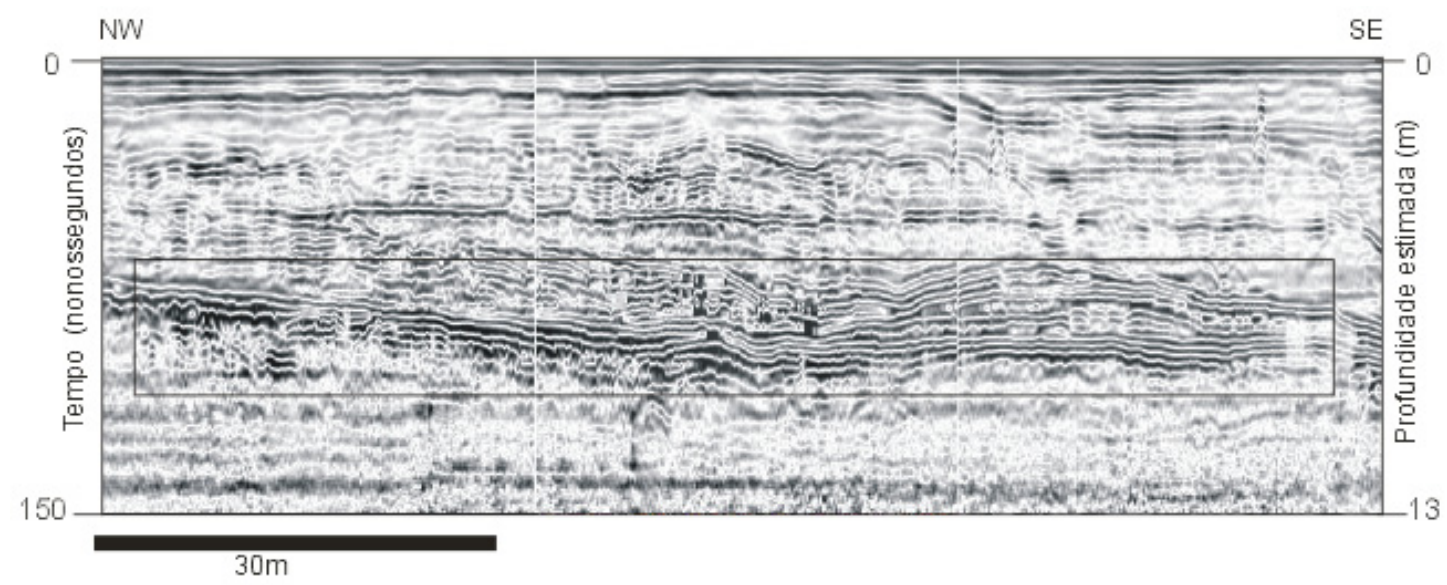

Figura 5 - Reflexões do tipo 2 (paralelas a sub-paralelas), indicada pelo retângulo. Notar a falta de reflexões abaixo deste intervalo, o que registra sensível atenuação das ondas eletromagnéticas provavelmente associada com a presença de lama (Seção 55, ver Fig. 1 para localização).

Figure 5 - Type 2 reflections (parallel and sub-parallel), indicated by the rectangle. Note the absence of reflections below this interval, marked by a rectangular contour, which records a sensible attenuation of the electromagnetic waves probably associated with the presence of mud (Section 55; see Fig. 1 for location).

interceptadas verticalmente umas pelas outras (Fig. 6). As reflexões hiperbólicas ocorrem principalmente logo abaixo das reflexões do tipo 1 , em setores destes com gradientes acentuados. Reflexões hiperbólicas também foram observadas associadas a reflexões isoladas, com baixa continuidade lateral e inclinação forte a sub-vertical, atribuídas a traços de falhas e fraturas que se projetam até o embasamento. As reflexões hiperbólicas tipicamente possuem um núcleo contendo reflexões caóticas (ver descrição abaixo).

Interpretação: reflexões hiperbólicas são atribuídas à presença de contatos extremamente irregulares ao longo de superfícies inclinadas. A ocorrência de hipérboles logo abaixo de reflexões inclinadas associadas a traços de falhas e fraturas, bem como subjacentes a segmentos inclinados das reflexões do tipo 1, é plenamente consistente com esta interpretação. Sob tais circunstâncias, ocorrem reflexões que assumem a forma de hipérboles à medida que a antena se afasta da área causadora deste efeito (Van Heteren et al., 1998). Assim sendo, as reflexões hiperbólicas observadas na área de estudo não refletem uma fácies deposicional, mas atuam como ferramenta auxiliar no reconhecimento de superfícies estratigráficas chaves e falhas/fraturas.

\section{Tipo 4: oblíquo}

Descrição: Consiste em uma série de reflexões inclinadas de baixa continuidade, amplitude variável e

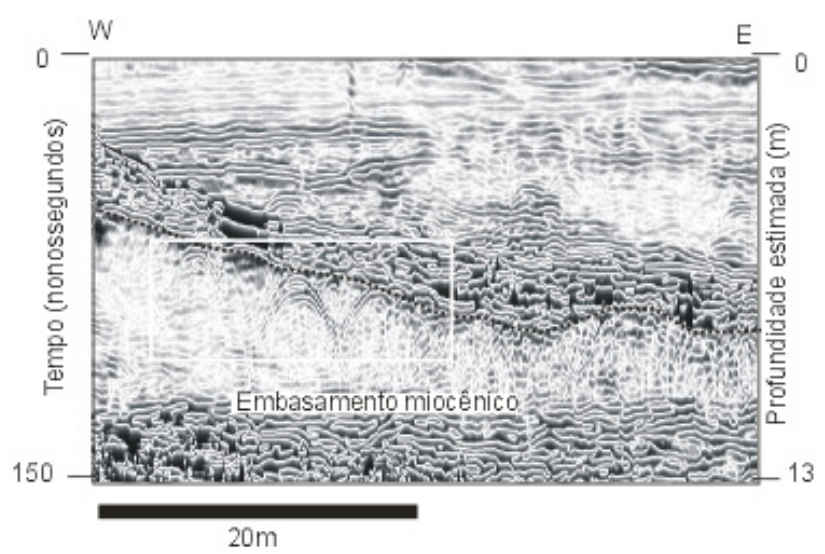

Figura 6 - Reflexões do tipo 3 (hiperbólicas), Seção 58, indicado pelo retângulo em linha brancas.

Figure 6 - Type 3 reflections (hyperbolic), Section 58, indicated by the white-lined rectangle.

alta freqüência, que se repete lateralmente caracterizando sinais curtos de padrão oblíquo (Figs. 7A-D). Estas reflexões (primeira ordem), ocorrem em grupos de mais ou menos 2 a $3 \mathrm{~m}$ de espessura, que são truncados por uma ordem superior de reflexões relativamente menos inclinadas e com maiores amplitudes (segunda ordem). As reflexões oblíquas são limitadas por uma terceira ordem de reflexões, terminando na base em downlap sobre reflexões com alta amplitude e boa continuidade lateral, que se mostram tabulares a ligeiramente sinuosas, enquanto os topos são truncados por, ou terminam em, toplap contra reflexões tabulares e de alta amplitude que ocorrem imediatamente acima delas (Fig. 7A). Padrões oblíquos dos tipos paralelo, tangencial, sigmoidal e sigmoidal complexo foram 
discriminados em função da forma, tipo de terminação e grau de convergência interna das reflexões (Figs. 7A-D). Os padrões paralelo e tangencial mostram características similares, com reflexões inclinadas cujas terminações superiores são truncadas abruptamente pelas reflexões sobrejacentes (Figs. 7A-C) Porém as terminações inferiores das reflexões paralelas são mais abruptas, formando um alto ângulo com as reflexões sobrejacentes, enquanto que as reflexões tangenciais
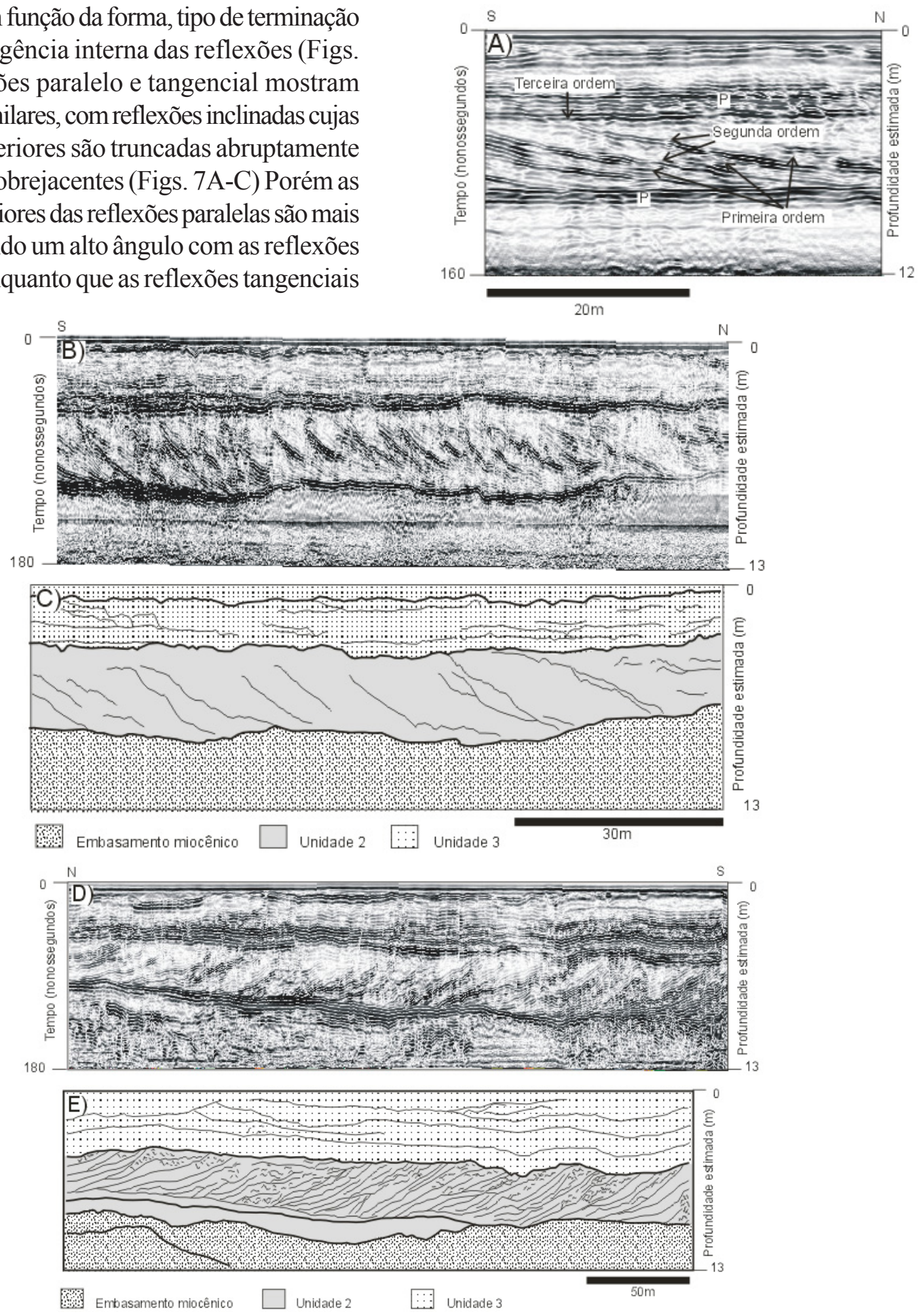

Figura 7 - Reflexões do tipo 4 (oblíquas), ilustrando: A) Oblíqua tangencial (Seção 76). B) Seção de radar e C) desenho sobre seção ilustrando reflexões oblíquas paralela a suavemente tangencial (Seção 77). D) Seção de radar e E) desenho sobre seção ilustrando reflexões oblíquas sigmoidal-complexa (Seção 76 e parte sul da Seção 83). Notar em A reflexões do tipo paralela a sub-paralela (P) acima e abaixo das reflexões oblíquas (ver localização das seções na Fig. 1). Notar, também, nesta figura superfícies de descontinuidade de primeira a terceira ordem (ver texto para mais explicações sobre o significado destas superfícies).

Figure 7 - Reflections of type 4 (oblique), illustrating: A) Oblique-tangential (Section 76). B) Radar section and C) drawing over section illustrating oblique parallel to slightly tangential reflections (Section 77). D) Radar sections and E) drawing over section illustrating oblique sigmoidal-complex reflections (Section 76 and southern portion of Section 83). Note in A parallel to sub-parallel reflections (P) above and below the oblique reflections (see section location in Fig. 1) Note, also, in this figure, discontinuity surfaces of first and third order (see text for further explanations on the meaning of these surfaces). 
possuem forma ligeiramente côncava uma vez que suas terminações inferiores terminam suavemente sobre as reflexões inferiores. Reflexões to tipo sigmoidal mostram topo e base com terminações suaves em downlap e toplap, respectivamente. O tipo sigmoidal complexo, mais freqüentemente observado na área de estudo (Fig. 7D), consiste em sinais de radar sigmoidais caracterizados pela combinação de reflexões sigmoidal e tangencial. As reflexões deste tipo 4 podem formar fácies eletromagnéticas de grande espessura, na ordem de 90 ns (estimadamente cerca de $7 \mathrm{~m}$ ), e com geometria que varia entre lenticular a tabular, estando em sua maioria direcionadas para sudoeste.

Interpretação: De um modo geral, padrões de reflexões oblíquas indicam deposição em ambiente com energia moderada a alta, elevado suprimento sedimentar e seguindo uma direção preferencial paralela ao registro das seções de radar. Este tipo de padrão de reflexões pode se formar sob diferentes circunstâncias deposicionais (p.e., migração de formas de leito, progradação de frentes deltaicas, migração de barras fluviais), sendo que sua interpretação na área de estudo deve ser analisada dentro do contexto ambiental mais provável. A excelente penetratividade das ondas eletromagnéticas nos depósitos apresentando reflexão oblíqua sugere a presença de areias secas, com pouco ou nenhuma argila e silte intercalados. Este fato, associado à documentação prévia de que processos eólicos tiveram uma importante participação na formação dos Sedimentos Pós-Barreiras, levaram à interpretação de que pelo menos grande parte das reflexões oblíquas observadas nas seções analisadas resultaram, mais provavelmente, da migração de dunas eólicas. Esta interpretação é consistente com o fato de que reflexões oblíquas mostram-se orientadas preferencialmente para sudoeste, direção coincidente com a migração das dunas ativas atuais existentes na Praia do Atalaia. O predomínio de reflexões com padrão sigmoidalcomplexo atesta uma história de deposição que inclui alternâncias de fases com agradação e migração lateral, acompanhada de erosão do topo da duna em ambiente de alta energia. As reflexões de primeira ordem são atribuídas à deposição ao longo dos foresets, enquanto que as de segunda ordem a superfícies de reativação, cuja abundância indica inúmeras alternâncias entre deposição e erosão na frente da duna durante o processo de migração. As reflexões de terceira ordem que limitam as demais reflexões correspondem respectivamente às superfícies de erosão de base e topo da duna. As reflexões oblíquas de grande porte com forma paralela, tangencial, sigmoidal e sigmoidal-complexa sugerem migração de forma de leito simples de grande escala e com cristas retilíneas a ligeiramente sinuosas sob condições de energia e taxa de sedimentação variáveis.

\section{Tipo 5: corte e preenchimento.}

Descrição e Interpretação: este tipo caracterizase por conjuntos de reflexões paralelas e subparalelas, contínuas e descontínuas, bem como reflexões oblíquas tipicamente com ângulos de inclinação muito suaves (inferiores a $15^{\circ}$ ), que são limitadas externamente por reflexões de alta amplitude, apresentando base com forma côncava para cima e topo horizontal (Fig. 8A). Este conjunto de reflexões resulta em corpos contendo espessuras de até $60 \mathrm{~ns}$ (equivalente a pouco mais de $4 \mathrm{~m}$ ) e larguras de até $80 \mathrm{~m}$ na face das seções de radar. Reflexões do tipo 5 são interpretadas como resultantes do preenchimento de depressões que foram esculpidas negativamente, por erosão, dos estratos subjacentes. A gênese de tal padrão é associada à deposição em ambientes confinados a canalizações e/ou pequenas depressões interdunas, formando lagos.

\section{Tipo 6: hummocky}

Descrição: são reflexões lateralmente descontínuas, de alta amplitude, que representam um híbrido entre reflexões dos tipos subparalelo e hiperbólico, sendo caracterizadas por uma série de reflexões irregulares e subparalelas em segmentos curtos que se truncam e mostram forma convexa para cima, lembrando feições em hummocky (Fig. 8B). Porém, neste caso o relevo destas elevações é baixo, sendo muito inferior aos das reflexões hiperbólicas. Localmente, as reflexões em hummocky tornam-se mais pronunciadas caracterizando feições em mounds com dimensões horizontais de até $20 \mathrm{~m}$. Estas formas maiores mostram internamente uma série de reflexões 


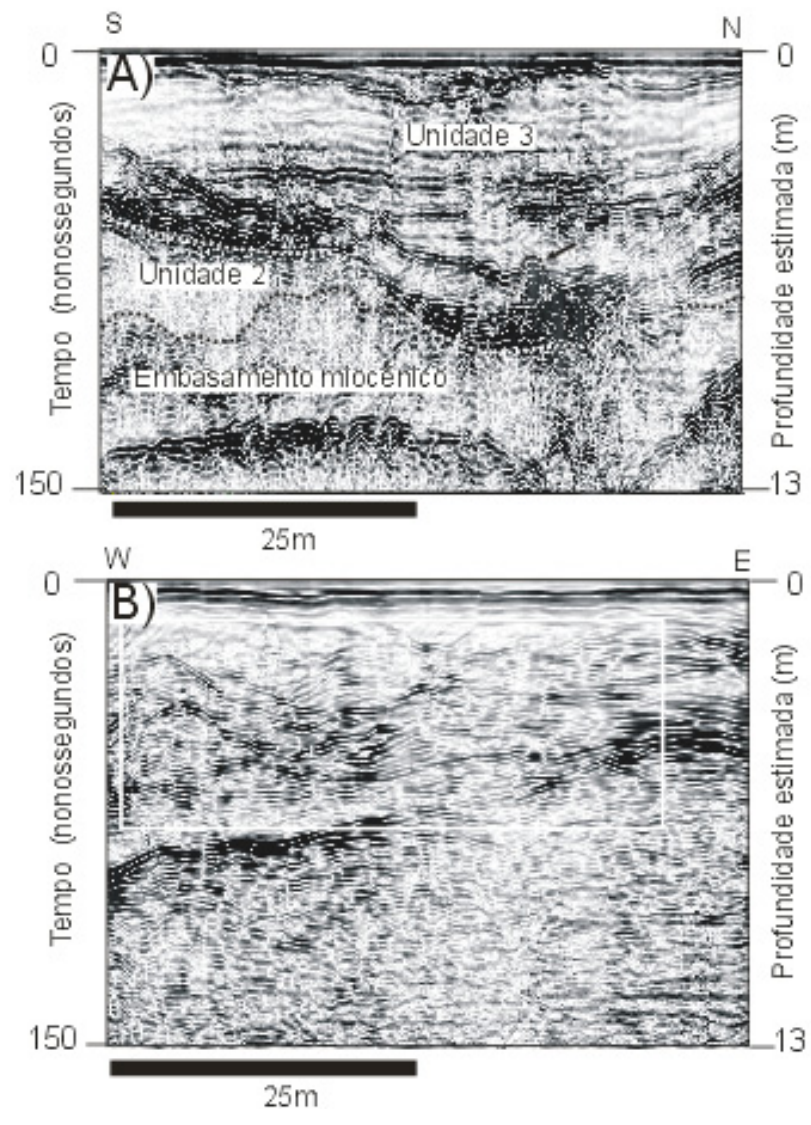

Figura 8 - A) Reflexões do tipo 5 (corte e preenchimento), Seção 82. Notar feição em mound internamente ao canal, atribuída à presença de matacão (seta). Notar, também, a complexidade interna dos depósitos de preenchimento de canal, representada por várias reflexões truncantes. B) Reflexões do tipo 6 (hummocky), presentes na Unidade 3, Seção 89.

Figure 8 -A) Type 5 reflections (cut and fill), Section 82. Note feature in mound within the channel, which is attributed to the presence of a boulder (arrow). Note, also, the internal complexity of the deposits filling the channel, represented by several truncating reflections. B) Reflections of type 6 (hummocky) from Unit 3, Section 89.

suavemente convexas ou inclinadas, com progradação em direções diversas. Mounds de até $30 \mathrm{~ns}$ de espessura (estimadamente $2 \mathrm{~m}$ ) contendo internamente reflexões concordantes com a forma externa achamse presentes na borda de uma ampla depressão no topo do embasamento miocênico (Fig. 9).

Interpretação: A grande maioria das reflexões deste tipo na área de estudo é atribuída à migração de formas de leito de médio porte, podendo representar áreas secas interdunas ou beach ridges. Seguindo esta interpretação, a forma convexa (hummocky) reflete a preservação da topografia destas formas de leito. As reflexões inclinadas progradacionais que são recobertas pelas reflexões em hummocky registram o desenvolvimento de foresets em direções diversas. Especula-se que o conjunto de mounds ocorrentes nas margens de depressões no embasamento miocênico possa estar associado à presença de matacões. Um análogo recente desta situação é representado por falésias costeiras na área de estudo, cuja erosão constante fornece uma grande quantidade de blocos lateritizados que se acumulam em sua base, próximo à zona de praia.

\section{Tipo 7: caótica}

Descrição e interpretação: são reflexões de baixa amplitude e continuidade, que se caracterizam por segmentos descontínuos e curtos, organizados sem uma orientação preferencial, formando uma série de reflexões aleatórias que podem se alternar com intervalos com reflexões paralelas a sub-paralelas. As reflexões caóticas gradam para as outras reflexões descritas acima ou, ainda, passam a áreas livres de reflexão ou com reflexão de muito baixa amplitude. Áreas com reflexões caóticas são associadas com litologias maciças, quer originalmente, quer devido a processos intempéricos (p.e., pedogênese).

\section{UNIDADES DE RADAR E ARCABOUÇO ESTRATIGRÁFICO}

A combinação dos dados de GPR obtidos na Praia do Atalaia permitiu reconstruir a paleotopografia sobre a qual ocorreu a deposição dos Sedimentos Pós-Barreiras (Fig. 10) Com base na análise das seções de radar, pode-se afirmar que a superfície de descontinuidade que separa a sucessão miocênica representada pelas formações Pirabas/Barreiras mostra relevo pronunciado, caracterizando depressões localizadas (Figs. 10-12), algumas das quais com profundidades superiores ao limite das seções de radar (de aproximadamente $13 \mathrm{~m}$ ). Além da superfície basal, o mapeamento de duas outras superfícies de descontinuidade, também definidas por reflexões do tipo 1, serviram de base para a individualização de três unidades de radar (Figs. 11 e 13).

Unidade 1: consiste dos depósitos mais inferiores, que ocorrem diretamente sobre o embasamento 


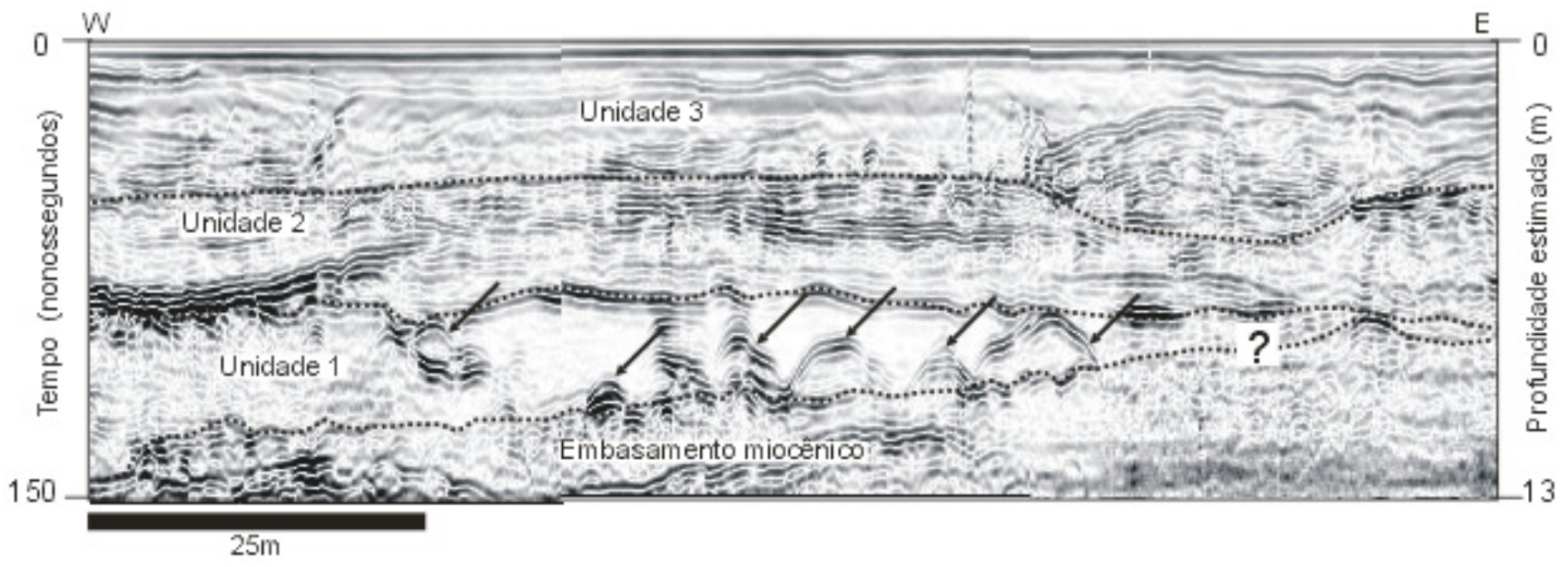

Figura 9 - Reflexões em hummockys proeminentes, resultando em feições do tipo mound sobre o embasamento miocênico (Seção 53, ver Fig. 1 para localização).

Figure 9 - Reflections with prominent hummockys, which result in mounds over the Miocene basement (Section 53, see Fig. 1 for location).

miocênico. Sua presença nas seções mapeadas é de natureza descontínua, tendo sido verificada apenas nas porções mais deprimidas da superfície de descontinuidade basal dos Sedimentos Pós-Barreiras (Figs. 11 e 12, seções 53-54, 55-56, 59 e 84). Nesta unidade basal, de espessura máxima equivalente a 80 ns (estimadamente $6 \mathrm{~m}$ ), dominam reflexões de muito baixa amplitude e, portanto, com padrões de difícil identificação, que intergradam com reflexões dos tipos oblíquo, tangencial e hummocky. Como interpretado anteriormente, estas reflexões oblíquas e hummocky podem estar associadas à presença de formas de leito de médio porte em regiões de interdunas e/ou beach ridges. Se esta interpretação for correta, então o domínio de depósitos arenosos com alta porosidade diretamente sobre depósitos relativamente menos porosos do embasamento miocênico (resultante do processo de homogeneização e ferrificação durante formação de paleossolo laterítico; Rossetti, 2000, 2001) pode ter resultado em intervalos com maior umidade, resultando nas reflexões de muito baixa amplitude. Além disto, é também neste intervalo que ocorrem feições em mounds, atribuídas a possíveis matacões depositados em encostas inclinadas, diretamente sobre o embasamento miocênico. Localmente, ocorrem pacotes de até $25 \mathrm{~ns}$, internamente constituídos de reflexões paralelas, sugestivos de deposição (de areia e/ou lama) em áreas planas (planícies, mangues, baixios) diretamente sobre a discordância basal.
Unidade 2: corresponde ao intervalo estratigráfico intermediário, de espessura máxima equivalente a $100 \mathrm{~ns}$, sendo mapeável através de praticamente todas as seções analisadas. Esta unidade acha-se separada da Unidade $1 \mathrm{e}$, mais comumente, dos depósitos miocênicos, através de superfície de descontinuidade (reflexões do tipo 1), a qual pode se apresentar localmente deprimida, formando concavidades que atingem até $40 \mathrm{~m}$ de extensão lateral no plano das seções de radar (Fig. 12). As reflexões típicas deste intervalo estratigráfico são dos tipos oblíquo, sigmoidal e sigmoidal-complexo, ocorrendo subordinadamente reflexões oblíquas paralela e tangencial. Importante salientar que estas reflexões oblíquas atingem suas maiores espessuras neste intervalo (até $7 \mathrm{~m}$ ) o qual, como proposto anteriormente, é atribuído ao registro da migração de dunas eólicas preferencialmente no sentido sudoeste. Comum nestes intervalos com reflexões oblíquas de grande porte são reflexões caóticas em suas porções mais superiores, formando áreas alongadas entre reflexões de primeira ordem, o que provavelmente reflete desmoronamentos gravitacionais episódicos dos sedimentos acumulados próximo ao ponto de inflexão da duna. Lateralmente, as reflexões oblíquas de grande porte gradam a reflexões do tipo hummocky, atribuída à migração de formas de leito menores, provavelmente em áreas de interdunas e/ou beach ridges. Áreas caracterizadas por reflexões paralelas e sub-paralelas, acham-se localmente presentes, bem como reflexões mistas que ocorrem 
em pacotes de, em média, 10 ns de espessura, constituídas de reflexões caóticas que gradam lateral e verticalmente a reflexões paralelas/sub-paralelas. Estas formam um arranjo de até 4 ciclos superpostos, sugerindo a repetição de processos relacionados à diminuição ascendente de energia, o que dentro do contexto ambiental proposto, pode sugerir deposição em planícies de maré progradantes. Outras reflexões presentes esporadicamente neste intervalo são do tipo hiperbólica, o que pode estar associada com zonas de falhas que se prolongam à partir do embasamento miocênico.

Unidade 3: corresponde à unidade de radar mais superior, de espessuras mais uniformes em torno de 50 a 100 ns. Neste intervalo dominam reflexões em hummocky (Fig. 14), seguidas do tipo oblíquo de médio porte, plano-paralelo e corte e preenchimento. Como esta unidade aflora em vários pontos da área estudada, pode-se recordar o domínio de areias finas, bem selecionadas, similares aos depósitos das dunas atuais. Além disto, a presença de reflexões plano- paralelas pode estar associada com o desenvolvimento de mangues, como ocorre no ambiente recente, também dominado por dunas e mangues. As reflexões de corte e preenchimento são bem representadas nesta unidade, caracterizando concavidades de até $50 \mathrm{~ns}$ de profundidade e $80 \mathrm{~m}$ de extensão lateral. Estas atingem os depósitos subjacentes da Unidade 2, erodindo-os localmente sob a forma de canais. Feição hiperbólica foi observada internamente a um dos canais presentes nesta unidade (Fig.11, Seção 82), sugestivo da presença de matacão.

\section{DISCUSSÃO E CONCLUSÃO}

A pesquisa pioneira com GPR conduzida na área de estudo representa um primeiro passo para a melhor caracterização litológica e estratigráfica dos Sedimentos Pós-Barreiras no norte do Brasil. Estes depósitos haviam sido apenas genericamente referenciados em trabalhos anteriores como

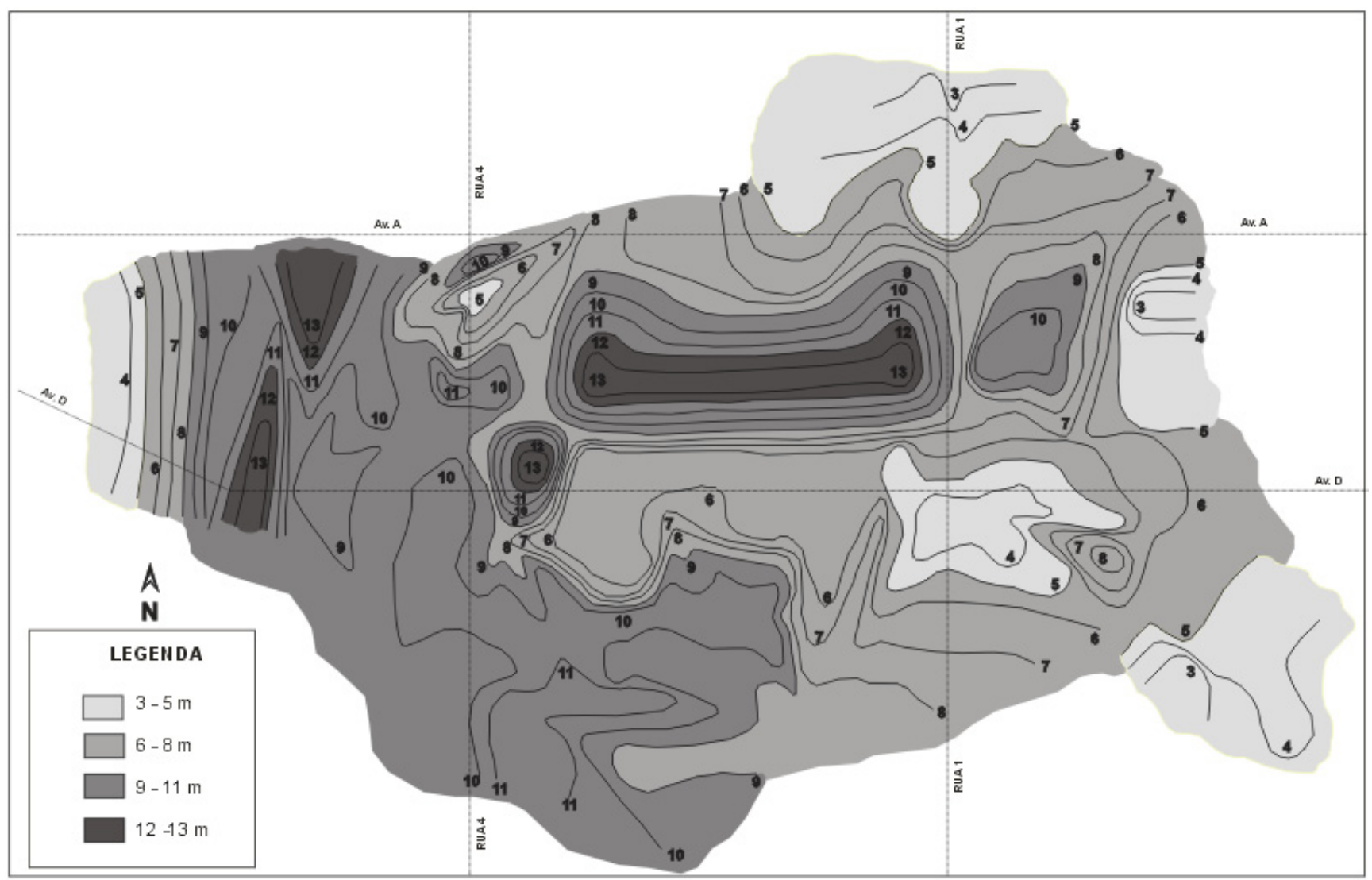

Figura 10 - Mapa de isópacas do topo do embasamento miocênico, ilustrando seu relevo pronunciado, com a presença de áreas deprimidas, que serviram de espaço para a acomodação dos Sedimentos Pós-Barreiras.

Figure 10 - Isopach map from the top of the Micene basement, illustrating its strong relief, with depressed areas, which created space to accommodate the Pós-Barreiras Sediments. 

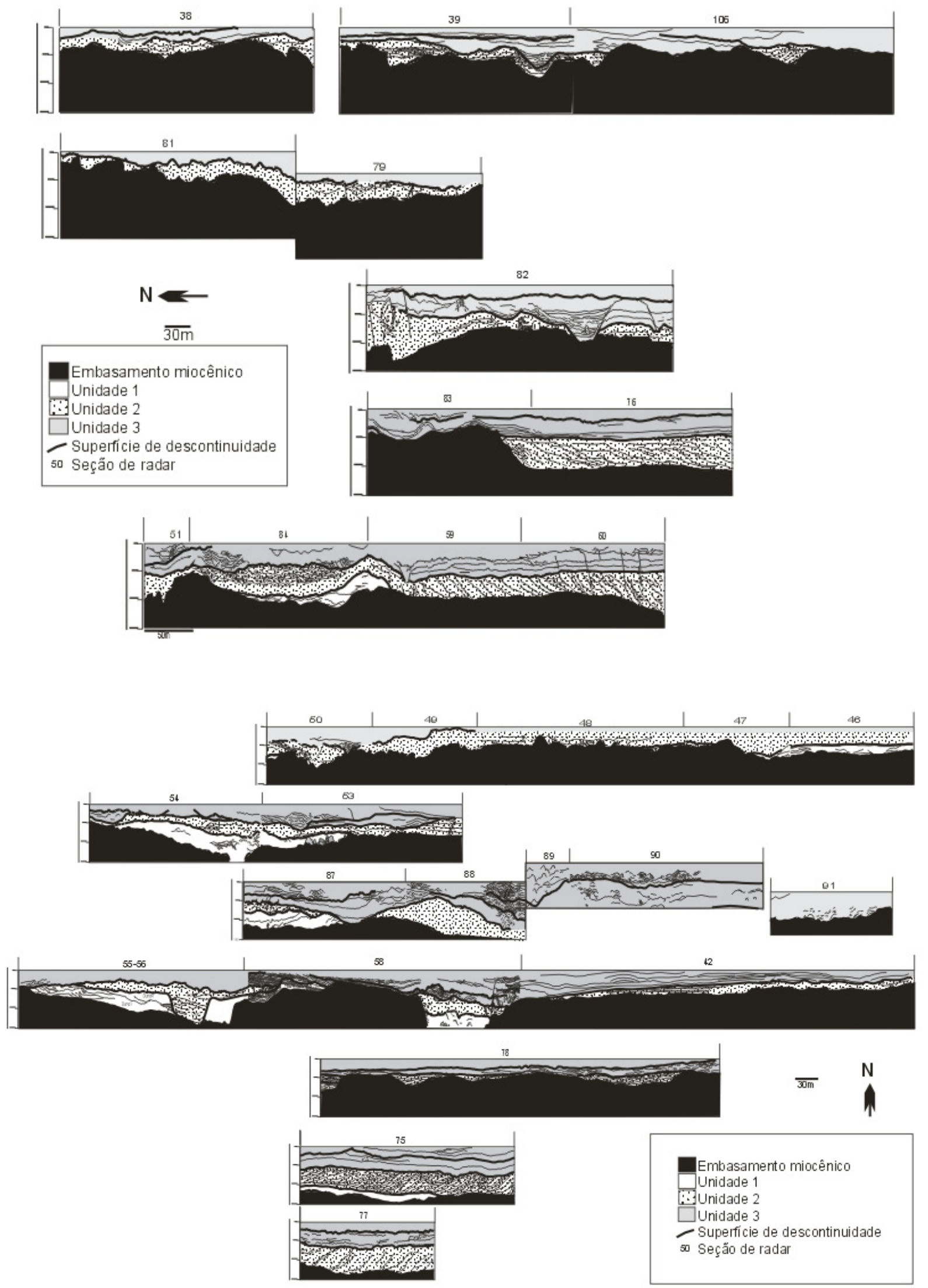

Figura 11 - Seções geológicas interpretadas a partir de dados de radar. A) sentido N-S. B) sentido E-W (ver Fig. 1 para localização). Figure 11 - Geological sections interpreted from radar data. A) N-S direction. B) E-W directions (See Fig. 1 for location). 

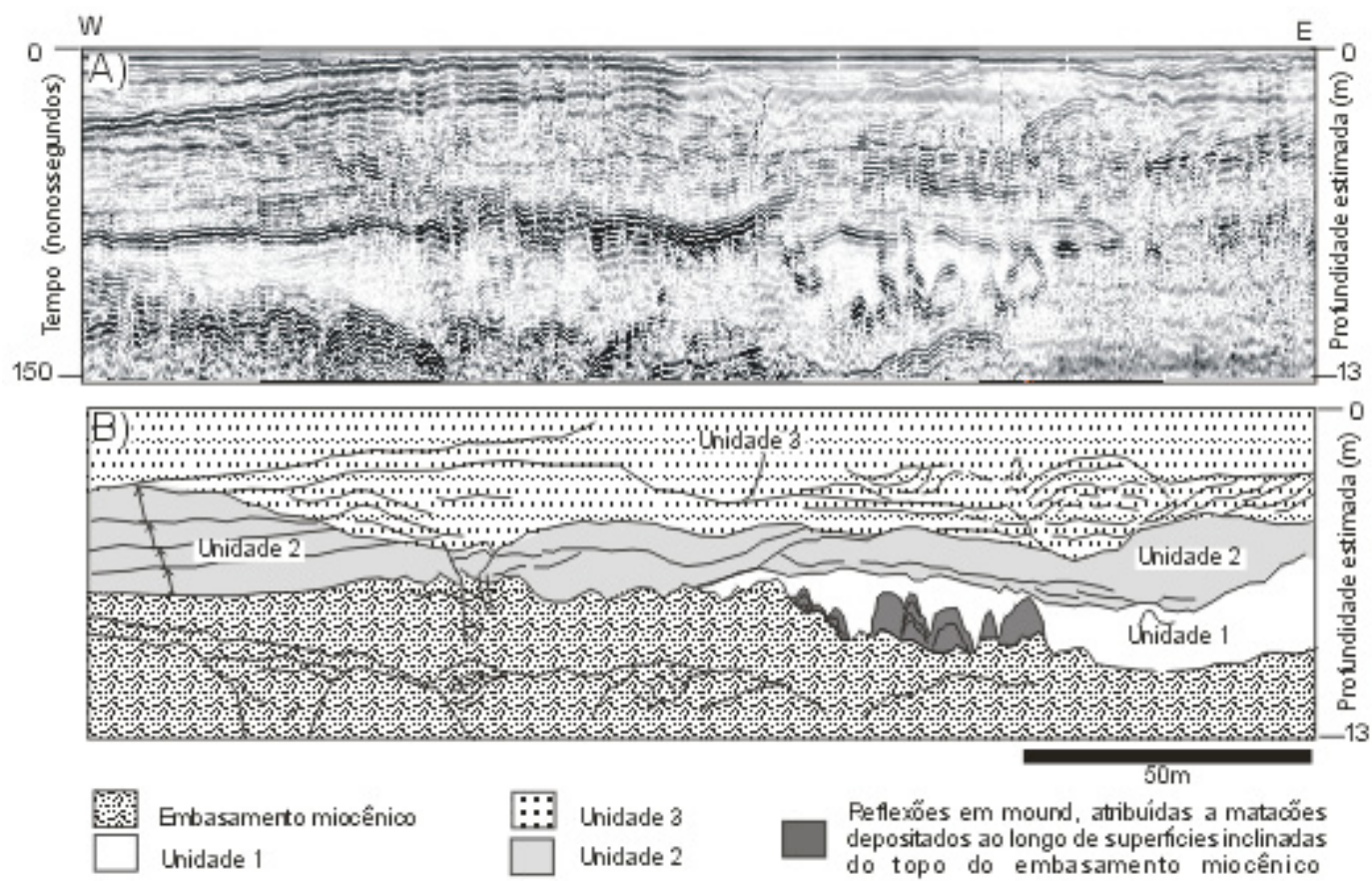

Figura 12 - Seção de radar 53 (A) com sua correspondente seção geológica interpretada (B), ilustrando o embasamento miocênico sendo sobreposto pelas três unidades estratigráficas mapeadas na Praia do Atalaia (ver localização da seção na Fig. 1).

Figure 12 - Radar section $53(\boldsymbol{A})$ with its corresponding interpreted geological section (B), illustrating the Miocene basement and the overlying three stratigraphic units mapped in the Praia do Atalaia (see location of the sections in Fig. 1).

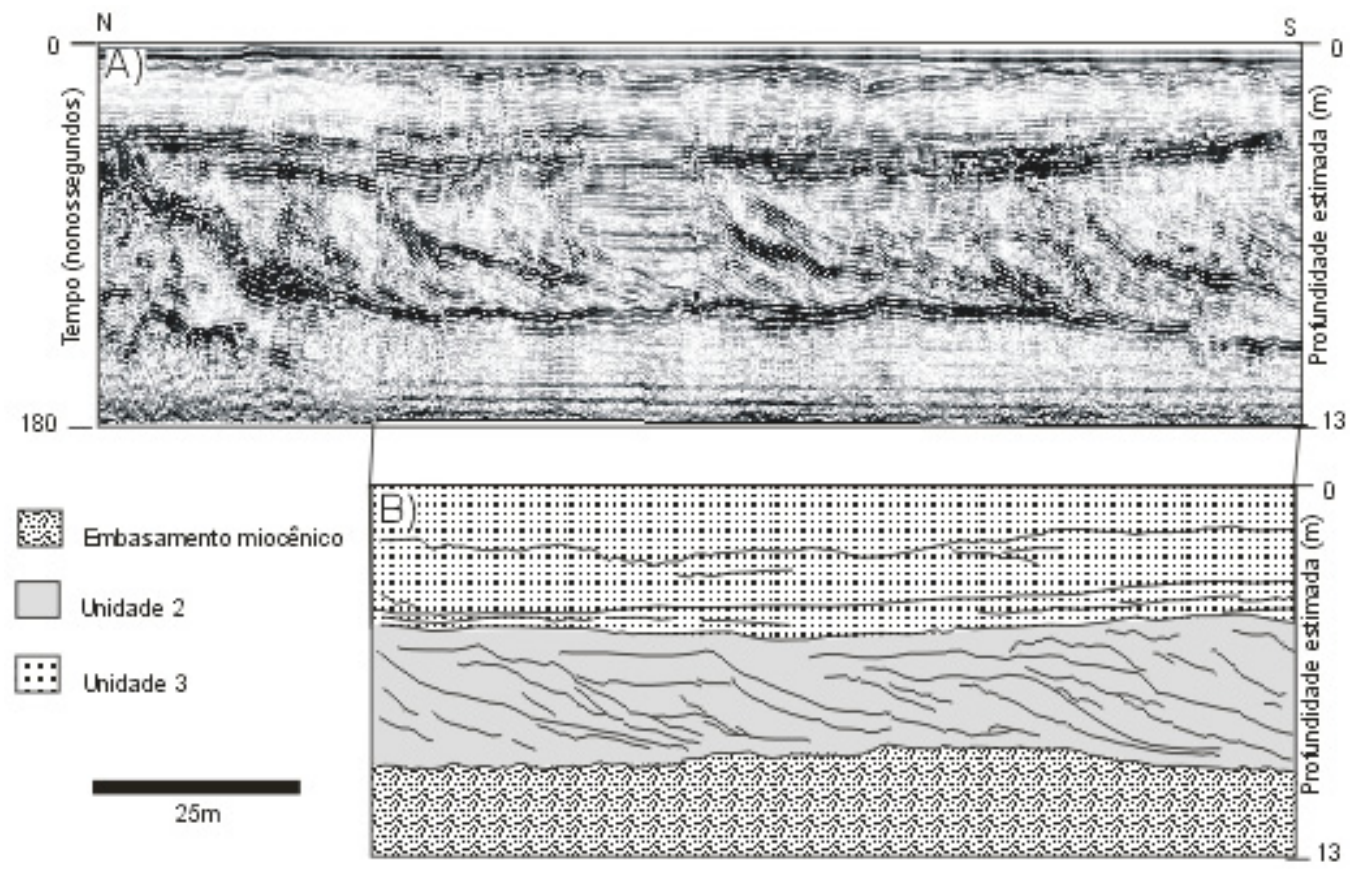

Figura 13 - Seções de radar (Seção 76 e parte sul da Seção 83) ilustrando o embasamento miocênico sendo diretamente recoberto pelas unidades 2 e 3. Notar a presença de reflexões oblíquas de grande porte na Unidade 2, atribuídas à migração de dunas eólicas. Notar, ainda, o considerável relevo erosional no topo do embasamento miocênico, formando depressões que serviram de sítios para a preservação de dunas eólicas na Unidade 2 (ver localização das seções na Fig. 1).

Figure 13 - Radar sections (Section 76 and southern portion of Section 83), illustrating the Miocene basement overlain by units 2 and 3. Note the large-scale oblique reflections in Unit 2, attributed to migration of eolian dunes. Note, also, the remarkable erosional relief at the top of the Miocene basement, which resulted from depressions that accommodated the eolian dune deposits present in Unit 2 (see location of the sections in Fig. 1). 


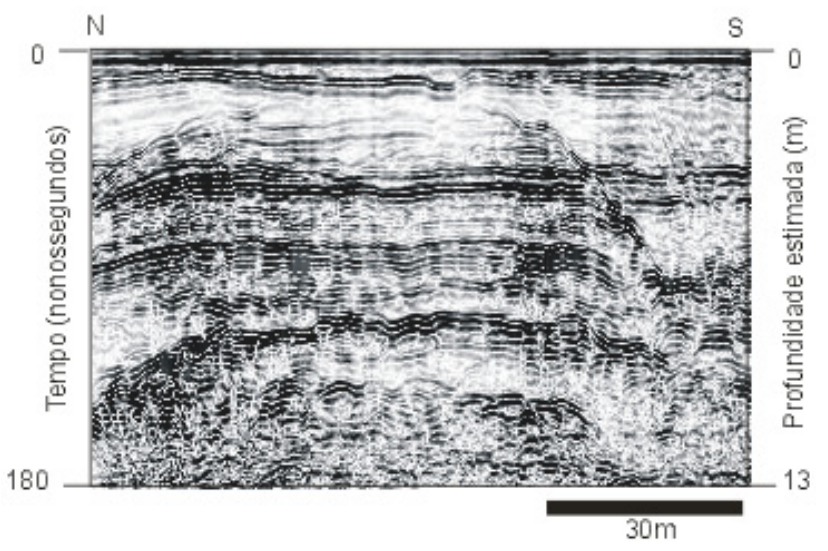

Figura 14 - Reflexões mistas combinando reflexões caóticas e paralelas que se alternam formando ciclos atribuídos à passagem ascendente de areia para argila (Seção 82).

Figure 14 - Mixed reflections combining chaotic and parallel reflections that are intergraded, forming cycles attributed to the upward grading of sand into mud (Section 82).

representativos de um intervalo arenoso, de aspecto ora maciço ora com estruturas de dissipação de dunas eólicas (Rossetti, 1989, 2000). A análise de aproximadamente $4 \mathrm{~km}$ de seções de radar na Praia do Atalaia permitiu uma separação precisa entre estes depósitos e o embasamento miocênico subjacente. Este contato é definido através de uma discordância marcada por forte relevo erosivo, facilmente mapeável através da área de estudo devido à presença de reflexões de alta amplitude do tipo 1, às quais se associam múltiplos que ressaltam ainda mais estas reflexões. Os Sedimentos Pós-Barreiras assentamse diretamente sobre esta discordância, sendo suas maiores espessuras verificadas em áreas com maior espaço de acomodação, criado localmente pela presença de depressões topográficas superiores a 13 $\mathrm{m}$ de profundidade. O mapeamento desta discordância entre a Sucessão Pirabas/Barreiras e os Sedimentos Pós-Barreiras na área de estudo corrobora estudos anteriores (p.e., Rossetti, 2000, 2001), onde se propôs limite de seqüência correlacionável através de uma extensa área através da Zona Bragantina até, pelo menos, o norte da Bacia de São Luís-Grajaú em função de um período de emergência provavelmente de caráter mundial (evento Tortoniano) que se seguiu à transgressão miocênica média.

A análise das seções de radar permitiu, ainda, a discriminação de três intervalos estratigráficos nos Sedimentos Pós-Barreiras. A demonstração da distribuição regional dessas unidades e, principalmente, o estabelecimento de seu posicionamento temporal dentro da história pósmiocênica, são questões que deverão ser resolvidas com a continuidade dos estudos de sub-superfície utilizando-se GPR em outras áreas da Zona Bragantina, o que deve ser complementado com coleta de vibracores (devidamente orientada com base nas seções de GPR). Entretanto, comparações dos resultados do presente estudo com seções de radar obtidas na Ilha do Outeiro, localizada a cerca de $270 \mathrm{~km}$ a SW da área de estudo (Rossetti \& Góes, 2001), sugerem que estas unidades podem ter sido geradas por fatores outros que não relacionados exclusivamente a processos sedimentares. Se assim o for, então a caracterização dessas unidades estratigráficas torna-se fundamental à reconstituição dos eventos pós-miocênicos que influenciaram a dinâmica de sedimentação no norte do Brasil.

Os dados disponíveis sugerem que após o episódio de rebaixamento do nível do mar relativo no

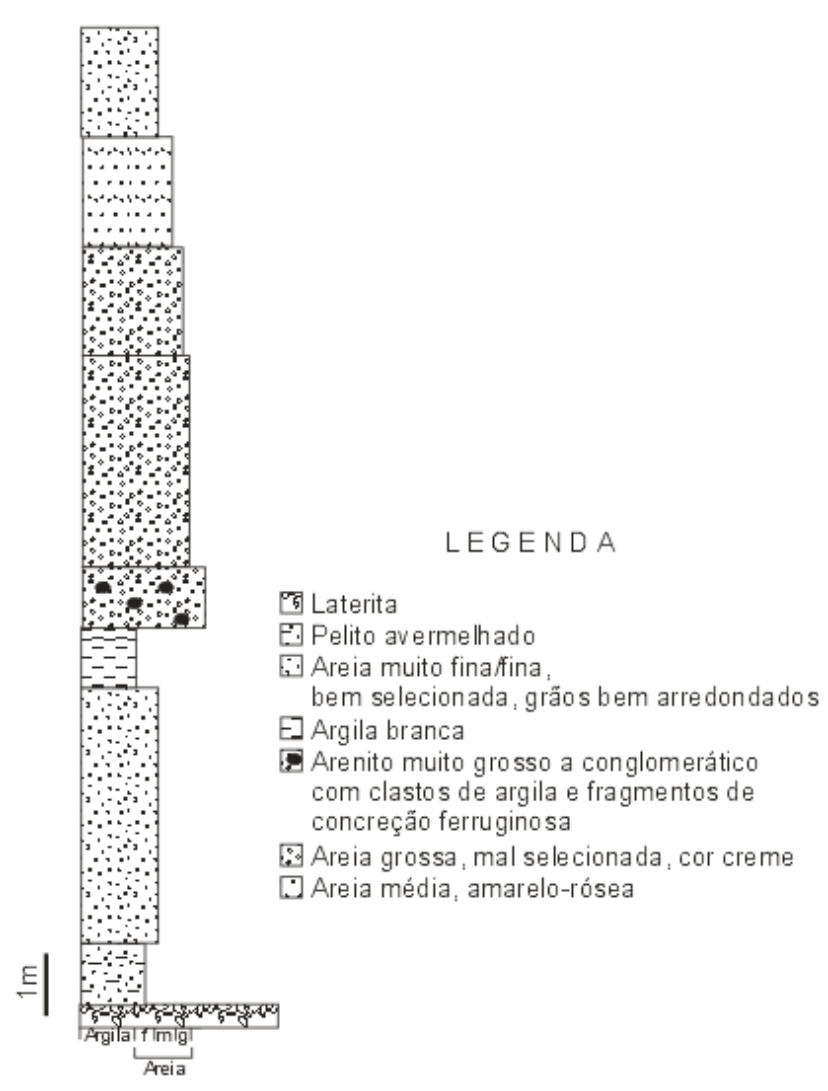

Figura 15 - Perfil vertical com registro da litologia descrita a partir de sondagem para poço artesiano na área de estudo.

Figure 15 - Vertical profile indicating the lithologies described from a well log in the study area. 
final do Mioceno-Plioceno Inferior?, houve um momento de transgressão, processo este que resultou no preenchimento de depressões topográficas, com deposição da Unidade 1. Sugere-se que pacotes com reflexões plano-paralelas na base desta unidade registrem deposição de lama/areia em embaiamentos, circundados por dunas eólicas e/ou beach ridges. Especula-se que este momento de subida do nível do mar relativo possa corresponder à transgressão registrada a cerca de $3 \mathrm{Ma}$, e que resultou no acúmulo de uma delgada sucessão estuarina diretamente sobre a discordância marcada por paleossolo laterítico do topo da Formação Barreiras (Mörner et al., 2001), a qual teve também reflexo em outras áreas da América do Sul (Mörner, 1991; Bidegain, 1991). Após o período de inundação, novo rebaixamento do nível de base levou à erosão do topo da Unidade 1 , resultando no desenvolvimento de uma segunda superfície de descontinuidade. Durante este processo, implantaram-se amplas canalizações, como sugerido pelas reflexões em corte e preenchimento que chegam a localmente erodir toda a unidade subjacente. $\mathrm{O}$ acompanhamento de perfurações de poços artesianos no local revelou a presença de areias com granulometria grossa a muito grossa e mal selecionada, e conglomerados com fragmentos de argila e concreções ferruginosas em nível correlato à Unidade 1 (Figs. 15), sugerindo a implantação de canalizações fluviais, o que poderia estar associada com o rejuvenescimento de drenagens durante o rebaixamento do nível do mar. Seguindo-se à esta fase de queda, houve momento favorável ao desenvolvimento de dunas eólicas de grande porte que preencheu a topografia negativa, como registrado pelo predomínio de reflexões oblíquas de grande porte, típicas da Unidade 2. É possível que também neste tempo tenha havido a progradação de planícies de maré lateralmente às dunas, como sugerido por ciclos sucessivos de reflexões mistas caóticas e planoparalelas, atribuídas à passagem ascendente de arenitos a argilitos (i.e., fining upward). O momento desta subida do nível do mar é incerto, porém é interessante lembrar que estudos palinológicos registram período de mar alto durante o Holoceno Médio na Amazônia Oriental (Behling et al., 2000; Behling \& Costa Lima, 2000), ao qual poderia estar associado o registro da área de estudo. Após isto, pelo menos uma outra queda do nível de base é documentada pela superfície de descontinuidade entre as unidades 2 e 3, que é recoberta por depósitos de origem predominantemente eólica interdigitados com depósitos de mangues e, localmente canais de maré, então correspondentes à história holocênica mais recente.

\section{AGRADECIMENTOS}

Ao FUNTEC/SECTAM e ao CNPq (461536/00-5), pelo auxílio financeiro. Os agradecimentos são extensivos a Jackson Douglas da Silva Paz, Cláudia Cristina de Melo, Heloísa Maria Santos e Leandro Miranda, pela assistência nos trabalhos de campo. Os autores também expressam seus agradecimentos ao revisor anônimo, que colaborou substancialmente para melhorar a qualidade deste artigo.

\section{REFERÊNCIAS}

Arai, M., 1997. Dinoflagelados (Dynophiceae) miocênicos do Grupo Barreiras do nordeste do Estado do Pará (Brasil). Revista Universidade de Guarulhos, 2:98-106.

Arai, M., Uesugui, N., Rossetti, D.F. \& Góes, A. M., 1988. Considerações sobre a idade do Grupo Barreiras no nordeste do Estado do Pará. In: SBG, Congr. Bras. Geol., 35, Belém, Anais, 2:738-752.

Asprion, U., 1998. Ground-penetrating radar (GPR) analysis in aquifer-sedimentology: case studies, with an emphasis on glacial systems of SW Germany. Tübinger Geowissenschaftliche Arbeiten, 43:1-105.

Behling, H. \& Costa Lima, M., 2000. Holocene environmental changes from the Rio Curuá Record in the Caxiuanã Region, eastern Amazon Basin. Quaternary Research, 53:369-377.

Behling, H., Cohen, M.C.L. \& Lara, R.J., 2000. Studies on Holocene mangrove ecosystem dynamics of the Bragança Peninsula in northeastern Pará, Brazil. Palaeogeography, Palaeoclimatology, Palaeoecology, 167:225-242.

Bidegain, J.C., 1991. Sedimentary development, magnetostratigraphy and sequence of events of the Late Cenozoic in Entre Rios and surrounding areas in Argentina. Paleogeophysics \& 
Geodynamics, Stockholm University, Stockholm, Tese de Doutorado.

Bridge, J.S., Alexander. J., Collier, R.E.L., Gawthorpe, R.L. \& Jarvis, J., 1995. Groundpenetrating radar and coring used to study the large-scale structure of point-bar deposits in three dimensions. Sedimentology, 42:839-852.

Dagallier, G., Laitinen, A. I., Malartre, F., Van Campenhout, I.P.A.M. \& Veeken, P.C.H., 2000. Ground-penetrating radar: application in a shallow marine Oxfordian limestone sequence located on the eastern flank of the Paris Basin, NE France. Sedimentary Geology, 130:149-165.

Góes, A.M., Rossetti, D.F., Nogueira, A.C.R. \& Toledo, P.M., 1990. Modelo deposicional preliminar da Formação Pirabas no nordeste do estado do Pará. Boletim do Museu Paraense Emílio Goeldi, Série Ciências da Terra, 2:3-15.

Knoll, M.D., Haeni, F.P. \& Knight, R.J,. 1991. Characterization of sand and gravel aquifer using ground-penetration radar, Cape Cod, Massachusetts. In G.E Mallard \& D.A. Aronson (eds.) U.S. Geological Survey Toxic Waste Hydrology Program-Proceedings of Technical Meeting. Monterey, CA, Geological Survey Water Resources Investigations Report 91-4034:29-35.

Leite, F.P.R., Oliveira, M.E.B., Arai, M. \& Truckenbrodt, W., 1997a. Palinoestratigrafia da Formação Pirabas e Grupo Barreiras, Mioceno do nordeste do estado do Pará, Brasil. Revista Universidade Guarulhos 2:141-147.

Leite, F.P.R., Oliveira, M.E.B., Oliveira, P.E., Capelato, M.S.S., Arai, M. \& Truckenbrodt, W., 1997b. Palinofloras miocênicas da Formação Pirabas e Grupo Barreiras na Região Bragantina, Estado do Pará, Brasil. Revista Universidade de Guarulhos 2:128-140.

Mörner, N.-A., 1991. The Patagonian glaciations and the onset of general Quaternary-type glaciations on the globe. Bol. IG-USP, Publicação Especial, 8:109-115.

Mörner, N.-A., Rossetti, D.F. \& Toledo, P.M., 2001. The amazonian rainforest: only some 6-5 million years old. In I.C.G. Vieira, J.M.C. Silva, D.C. Oren \& M.A. Dincao (eds.) Diversidade
Biológica e Cultural da Amazônia. Belém, Editora do Museu Paraense Emílio Goeldi, p. 3-18.

Payton, C.E., 1977. Seismic stratigraphy: application to hydrocarbon exploration. Am. Assoc. Pet. Geol. Mem., 26:516 p.

Rossetti, D.F., 2000. Influence of low amplitude/ high frequency relative sea-level changes in a wave-dominated estuary (Miocene), São Luís Basin, northern Brazil. Sedimentary Geology, 133:295-324.

Rossetti, D.F., 2001. Late Cenozoic sedimentary evolution in northeastern Pará, within the context of sea level changes. Journal of South America Earth Sciences, 14:77-89.

Rossetti, D.F., Góes, A.M., 2001. Imaging Upper Tertiary to Quaternary deposits from northern Brazil applying ground penetrating radar. Revista Brasileira de Geociências, 31:195-202.

Rossetti, D.F., Truckenbrodt, W. \& Góes, A.M., 1989. Estudo paleoambiental e estratigráfico dos Sedimentos Barreiras e Pós-Barreiras na região Bragantina, nordeste do Pará. Boletim do Museu Paraense Emílio Goeldi, Série Ciências da Terra 1:25-74.

Rossetti, D.F., Góes, A.M. \& Truckenbrodt, W., 1990. A influência marinha nos Sedimentos Barreiras. Boletim do Museu Paraense Emílio Goeldi, Série Ciências da Terra 2:17-29.

Silva, F.G. \& Scherer, C.M.S., 2000. Morphological characterization of ancient aeolian dunes using the ground-petrating radar, Botucatu Formation, southern Brazil. Revista Brasileira de Geociências, 30:531-534.

Ucha, J.M., Vilas Boas, G.S., Botelho, M., Ribeiro, L.P. \& Santana, P.S., 1999. Utilização de radar de penetração no solo-GPR na identificação das camadas de fragipã e de duripã nos solos desenvolvidos sobre os sedimentos do Grupo Barreiras. In: SBG, Congr. da ABEQUA, 7, Porto Seguro, Resumos.

Van Heteren, S., Fitzgerald, D.M., Mckinlay, P.A. \& Buynevich, I.V., 1998. Radar facies of paraglacial barrier systems: coastal New England, USA. Sedimentology, 45:181-200. 